\title{
Estudos preliminares em taioba (Colocasia sp.) nas condiçōes edafoclimáticas de Manaus (1)
}

\author{
Waldelice Oliveira de Paiva $\left({ }^{2}\right)$, Peter Weigel $\left({ }^{2}\right)$, Danilo F. da Silva Filho $\left({ }^{2}\right)$ e Francisco M. Machado $\left({ }^{2}\right)$
}

\section{Resumo}

No estudo de avaliação do comportamento da taioba (Colocasia sp.), introduzida no Município de Manaus, Estado do Amazonas, mostrou que a exploração desta cultura é promissora com produção média de tubérculos equivalente a 10,63 ton/ha. Através de observações fenotipicas do caráter precocidade na produção, as plantas antes da colheita foram agrupadas em quatro classes. Foi detectada diferenças estatísticas significativas entre as classes. A Classe 4 (com continuidade vegetativa) foi a mais produtiva, porém tardia, enquanto que as classes 1 e 2 (com mais que 8 folhas e 1 a 7 folhas rebrotadas, respectivamente) apesar de apresentarem menor produção são mais precoces, podendo ser aproveitadas para obtenção de duas colheitas anuais. 0 estudo de correlações fenotípicas entre caracteres dentro de classes, mostrou associação positiva e sígnificativa para as classes 1,2 e 3 . A seleção de rizomas com maior peso contribuirá efetivamente na formação de uma população clonal mais promissora.

\section{INTRODUÇÃo}

O Estado do Amazonas por não possuir condições fotoperiódicas exigidas para a produção de batata (Solanum tuberosum) é por excelência importador deste produto, ficando à marcê da majoração das tarifas de transportes e do alto indice de perdas, ocasionadas principalmente por um sistema viário deficiente. Devido a estes fatores, o preço final do produto normalmente é elevado, deixando as classes menos favorecida sem condições de adquirí-lo. Assim o cultivo de tuberosas adaptadas às condições climáticas regional é importante tanto como fonte de alimentação suplementar como diversificação do mercado (Albuquerque \& Pinheiro, 1970).

Entre as inúmeras espécies que produzem tubérculos amiláceos nas condições tropicais, encontram-se as pertencentes aos gêneros $\mathrm{Co}$ - locasia e Xanthosoma cujos tubérculos são vulgarmente denominados de taioba. O gênero Cclocasia é originário dos países asiáticos, e atualmente é conhecido e cultivado nos demais continentes (Massal \& Barral, 1956; Jonker-Vet Hoef, 1959; Kirck, 1978), e citada por Ducke et al. (1975) como uma espécie de grande plasticidade, podendo adaptar-se às variações climáticas que vão desde os climas temperados secos até os tropicais úmidos. As exigências para sua adaptação concentra-se em áreas com $\mathrm{pH}$ 4.3-7.4, temperaturas médias anuais de $11-29^{\circ} \mathrm{C}$ e precipitação média anual entre $700-4.000 \mathrm{~mm}$. Segundo Martin \& Ruberté (1975); Oliveira \& Carvarho (1975) a Colocasia sp. é muito apreciada por seus tubérculos, embora suas folhas, da mesma maneira que as espécies do gênero Xanthosoma, possam ser utilizadas na alimentação. Van Reheenen (1962) menciona que quando cultivada por um período aproximado de 200 dias produz cerca de 6,5 $\mathrm{t} / \mathrm{ha}$ de tubérculos.

O objetivo deste trabalho é avaliar o comportamento da taioba (Colocasia sp.) nas condições edafo-climáticas do Município de Manaus. Estado do Amazonas, bem como obter informações que direcionem melhor um progrania de melhoramento desta cultura.

\section{MATERIAL E MÉTODOS}

O material utilizado no presente estudo foi introduzido no Campo Experimental de Olericultura do Inst:tuto Nacional de Pesquisas da Amazônia - INPA, situado no Km 14 da Rodovia AM-10, em Manaus, Estado do Amazonas. É constituído de plantas de taioba (Colocasia $\mathrm{sp.),}$ que foram propagadas vegetativamente em julho de 1978, em área de solo arenoso e

(1) - Trabalho integrante do projeto financiado pelo POLAMAZONIA/CNPq.

(2) - Instituto Nacional de Pesquisas da Amazônia, Manaus. 
baixa fertilidade, sem obedecer a um delineamento experimental. O objetivo inicial era so. mente avaliar o seu comportamento

Por ocasiäo do plantio foram aplicados 5 litros/cova de esterco de gado curtido. O espaçamento foi de $0,50 \mathrm{~m}$ entre plantas e $1,00 \mathrm{~m}$ entre linhas.

A colheita dos tubérculos, feita com certo atraso, foi aos treze meses de plantio em setembro/80. Antes do arranquio das plantas observou-se na área cultivada que as plantas poderiam ser agrupadas em quatro classes bem definidas. Esta classificação foi baseada em observações fenoípicas de acordo com o aspecto vegetativo das plantas. As classes $1 \mathrm{e}$ 2. com 514 e 350 plantas, respectivamente, foram consideradas as mais precoces, pois as foihas originais já haviam tombado e apresentavam brotações novas (mais que 8 folhas $\mathrm{e}$ de 1 - 7 folhas), oriundas dos tubérculos. A classe 3 representada por 204 plantas, cujo término do ciclo vegetativo coincidiu com a coIheita, apresentava-se totalmente desfolhada. A quarta classe, constituída de 169 plantas, permaneceu com as folhas originais, sem interromper o ciclo vegetativo.

Por ocasião do arranquio, os tubérculos foram separados do rizoma, limpos e pesados, anotando-se o peso tanto do rizoma como dos tubérculos por planta dentro das classes.

Para testar possíveis diferenças na produção entre as classes, efetuou-se a análise estatística utilizando o artifício apresentado por Steel \& Torrie (1960), onde cada planta foi considerada como uma repetição dentro das quatro classes. No teste de comparação entre médias foi utilizado o teste Tukey fazendo-se uso da seguinte expressáo apresentada por Pimentel Gomes 1978) :

$$
\Delta=q \sqrt{\frac{1}{2}\left(\frac{1}{r i}+\frac{1}{r j}\right)} 6 e^{2}
$$

As correlações fenotípicas entre os caracteres peso de rizoma (1) e produção de tubérculos (2) em uma mesma planta, dentro das quatro classes, bem como o teste " $\mathrm{t}$ ", seguiram a metodologia de Steel \& Torrie (1960).

\section{ReSUltados E DISCUSSÃO}

Na tabela 1 estão apresentados os resultados referentes à análise de variância, onde pode ser notada a diferença significativa ao nível de 0,01 de probabilidade entre as classes testadas, tanto para o peso de rizomas como para os tubérculos. Este resultado demonstra a existência de variação no ciclo vegetativo das plantas, podendo-se admitir que esta variação não é devida somente a fatores ambientais. Possivelmente, existe uma componente de origem genético-fisiológica controlando a duracão do ciclo vegetativo das plantas, tendo em vista que todas as plantas receberam o mesmo tratamento, e estavam sujeitas às mesmas variações ambientais dentro da área.

No teste de médias (tabela 2), observou-se diferença significativa ao nível de 0,05 de probabilidade para o caráter peso de rizoma, sendo que as classes 3 (plantas totalmente desfolhadas) e 4 (plantas com folhas originais) apresentaram as maiores médias, não detectandose diferenças significativas entre elas, entretanto estas classes diferiram das demais.

A classificação das plantas no campo antes do arranquio, foi baseada em observações de Martin \& Ruberté (1975) que verificaram a sensibilidade de Colocasia sp. a períodos com deficiência hídrica, ocasionando a morte das folhas e conseqüentemente a menor duração do ciclo vegetativo. As plantas das classes 1 e 2 , no momento da colheita dos tubérculos, iá haviam encerrado o ciclo vegetativo apresentando-se com folhas rebrotadas em diferentes estágios; neste caso, foram consideradas como as mais precoces em relação às plantas do outras classes, e consideradas também como as mais sensiveis à periodos de deficiência hídrica. Suas produções foram 9,18 e 10,49 $t$ /ha de tubérculos, respectivamente. A classe 3 (plantas cujo ciclo vegetativo havia terminado no momento da colheita), não diferiu significativamente da classe $2 \mathrm{em}$ termos de produção. As plantas da classe 4 foram fenotipicamente mais tardias e apresentavam continuidade do ciclo vegetativo no momento da collheita; sua produção foi equivalente a $12,53 \mathrm{t} /$ ha de tubérculos. Segundo Ducke et al, (1975) as plantas 
TABELA 1 - Valores e significância dos quadrados médios das análises de variância dos caracteres peso (em gramas) de rìzomas e produção (em gramas) de tubérculos em quatro classes, em taioba. Manaus-AM, 1980.

\begin{tabular}{lccc}
\hline Fonte de Variação & G.L. & $\begin{array}{c}\text { Peso de } \\
\text { Rizoma }\end{array}$ & $\begin{array}{c}\text { Produção de } \\
\text { Tubérculos }\end{array}$ \\
\hline Entre-classes & 3 & $19.402,196^{* *}$ & $876.694,876^{*}$ * \\
Dentro de classes & 1233 & $2.506,485$ & $41.032,789$ \\
\hline CV\% & & 47,113 & 38,630 \\
\hline
\end{tabular}

$\left({ }^{* *}\right)$ - Significativo oo nível de 0,01 de probabilidade pelo teste de $F$.

TABELA 2 - Médias dos caracteres peso (em gramas) de rizomas e produção (em gramas) de tubérculos, em quatro classes, em taioba. Manaus-AM, 1980.

\begin{tabular}{llll}
\hline Classes & \multicolumn{1}{c}{$\begin{array}{c}\text { Característica } \\
\text { Fenotípica }\end{array}$} & $\begin{array}{c}\text { Peso de } \\
\text { Rizoma }\end{array}$ & $\begin{array}{c}\text { Produção de } \\
\text { Tubérculos(1) }\end{array}$ \\
\hline 1 & folhas rebrotadas $(>8)$ & $100,36 \mathrm{~b}(2)$ & $459,70 \mathrm{c}(2)$ \\
2 & folhas rebrotadas $(1-7)$ & $101,82 \mathrm{~b}$ & $524,69 \mathrm{~b}$ \\
3 & desfolhadas & $116,37 \mathrm{a}$ & $516,69 \mathrm{~b}$ \\
4 & folhas originais & $115,26 \mathrm{a}$ & $626,30 \mathrm{a}$ \\
\hline
\end{tabular}

(1) - Valores méd os obtidos em grama por plonta.

(2) - Médias seguidas de mesma letra não diferem entre si, ao nível de 4,05 de probabilidade pelo teste de Tukey.

de taioba, de acordo com o ciclo vegetativo são classificadas como semiperenes, assim quanto maior for o período no campo, maior é a produção.

Como se pode inferir destes resultados, se as diferenças entre as classes forem devido a fatores internos da planta, ou seja, de ordem genético-fisiológica. as classes 1 e 2 serão as mais precoces, havendo, portanto, grande possibilidade de sucesso na seleção de plantas dentro de classes e, conseqüentemente, a formação de um clone com características de maior precocidade. Para confirmar tal hipótese. as plantas mais produtivas dentro de cada classe foram propagadas vegetativamente estando atualmente no campo de cultivo.
As estimativas dos coeficientes de correlação fenotípica entre os caracteres peso de rizoma e produção de tubérculos, para cada planta individualmente dentio de cada classe, estão apiesentados na tabela 3 . Observa-se uma forte associação positiva entre os carac. teres dentro das três primeiras classes, indicando que as plantas destas classes com os rizomas mais pesados apresentavam também maior produção de tubérculos. Neste caso a simples seleção fenotípica dos rizomas conduz efetivamente a uma maior produção; procedimento semelhante foi adotado em batata, com sucesso por Swiezynski (1978).

O coeficiente de correlação fenotípica entre os caracieres dentrc da classe 4 não diferiu estatisticamente de zero. Este fato, não afasta 
TABELA 3 - Coeficientes de correlação entre caracteres 1 e 2 em plantas dentro de classes, em taioba. Manaus-AM, 1980.

\begin{tabular}{cccc} 
Classes & $\begin{array}{c}\text { Graus de } \\
\text { Liberdade }\end{array}$ & $\begin{array}{c}\text { Característica } \\
\text { Fenotipica }\end{array}$ & $\begin{array}{c}\text { Caracteres Correla- } \\
\text { cionados } 1 \text { e } 2 \text { (a) }\end{array}$ \\
\hline 1 & 512 & folhas rebrotadas ( $>8)$ & $0,139^{* *}$ \\
3 & 348 & folhas rebrotadas (1-7) & $0,265^{* * *}$ \\
4 & 202 & desfolhadas & 0,0764 n.s. \\
\hline
\end{tabular}

(a) - Peso (em gramas) de rizoma (1) e produção (em gramas) de tubérculos (2).

$(* *)$ - Significativo a 0,01 de probabilidade pelo teste " $\mathrm{t}$ ".

$(n, s$.$) - Não significativo.$

a possibilidade de associação fenotípica entre os caracteres nesta classe, levando-se em conta que o número de plantas observadas nesta classe foi inferior ao das demais classes, o que possivelmente não tenha sido suficiente para caracterizar tal associação.

Os coeficientes de variação das análises mantiveram-se bastante elevados. Esta variação, entretanto, é em parte devida a falta de um cielineamento apropriado, sendo todos os erros incluídos na variação dentro de classes. Desta forma, os resultados obtidos devem ser aceitos com certas restrições.

\section{CONCLUSÕES}

- As observações fenotípicas do comportamento da taioba (Colocasia sp.) no Campo Experimental de Olericultura do INPA, foram consideradas extremamente promissoras para o cultivo desta hortaliça-tuberosa no Município de Manaus, Estado do Amazonas.

- A seleção das classes 1 e 2 ou seja, com mais que 8 folhas e 1 a 7 folhas rebrotadas, podem conduzir a uma população clonal com maior precocidade.

- A seleção de rizomas de maior peso deve ser eficiente para aumentar a produção de tubérculos.

\section{SUMMARY}

Preliminary observations are reported on the taro (Colocasia sp.) in Manaus, AM. The plants yielded the equivalent of $10.63 \mathrm{t} / \mathrm{ha}$. Based on phenotipyc observations, the plants were classified for early maturing and yield. Significant differences were detected for the characters. The yield of tuber roots in class 4 (plants with original leaves), was the best, but slowest. Classes 1 and 2 (more than eight and one to seven new leaves respectively) did not produce as leanly as class 4 , but are considered to be better in practice because of their early maturing. The character center corm weight showed a positive correlation with the yield of tuber roots in classes 1,2 and 3 . Thus screening for a bigger center corm will resulte in the formation of a more produtive cultivar.

\section{REFERENCIAS BIBLIOGRÁFICAS}

ALBUQUERQUE, M. \& PINHEIRO, E.

1970 - Tuberosas Feculentas. Série: Fitotecnia. Instituto de Pesquisas e Experimentação Agropecuárias do Norte. 1 (3): 33-47.

DUCKE, J.A.; HURST, S.J.; TERREL, E.E.

1975 - Ecological distribution of 1000 Economic Plants. Information Al Dia Alerta Agronomia, Turrialba, $n .^{\circ} 1,1-32$.

JONKER-VERHOEF, A.M. \& JONKER, F.P.

1959 - Notes on the Araceae of Suriname, 2 Med. bot. Mus. Rijksniv., Utrecht $n .{ }^{\circ} 154,139-155$.

KIRCK, P.V.

1978 - Indigenous Agriculture on Uvea (Western Polynesia) Economic Botany, New York, 32: 157-181. 
MARTIN, W.F. \& RUBERTEE, R.M.

1975 - Edibles leaves of the tropics. Mayaguez Institute of Tropical Agriculture, Puerto Rico. 235p.

MASSAL, E. \& BARRAL, J.

1956 - Food Plants of the south sea Islands. Tech. Pap. 94. S. Pacific. Comm. 51p.

OLIVEIRA, J.S. \& M.F. DE CARVALHO

1975 - Nutritional Value of some edible leaves used in Mozambique. Economic Botany New York, 29: 255-263.

PIMENTEL GOMES, F.

1978 - Curso de Estatistica Experimental Livraria Nobel, São Paulo, 8." ed. 430p.
STEEL, R.G.D. \& TORRIE, J.H.

1960 - Principles and Procedures of statistics. McGRAW HILL Book Company, New York. $481 p$.

SWIEZYNSKI, K.M.

1978 - Selection of individual tubers in potato breeding. Theor. Appl. Genet. New York, $53,71-80$.

VAN RHEENEM, H.A.

1962 - Report for the period 1 January 1961 to 30 September 1962. Agrarisch Proefstation. MANOKWARI, 86p. mimeo.

(Aceito para publicação em 19/03/81) 